\title{
Impressions from EASD 2020
}

\author{
Dr Caroline Day reports on the European Association for the Study \\ of Diabetes 56th annual meeting, aka VM2020
}

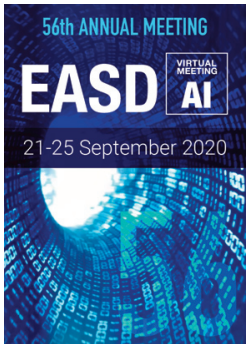

\section{Introduction}

The 56th Annual EASD meeting was due to be held in Vienna, but hopes of attending a conference in this cultural capital were dashed by the unstoppable advance and insidious occupation of the continent of Europe by COVID-19. Thus, for the first time the EASD annual meeting was located exclusively in cyberspace. Whilst this change of venue undoubtedly impacted negatively on businesses associated with the conference industry, the environmental benefits should not be underestimated. Indeed, the meeting was even more popular with 20,139 delegates $(14,562$ in 2019) from 141 countries, but the UK contingency dropped to 4th place with 957 delegates (988 in 2019), behind Brazil, Germany and Mexico.

\section{Abstracts and access}

Accessing an online flipbook from the virtual meeting or downloading a 310 page pdf of the final programme via your MyEASD account makes for easy navigation of the event (put your key word in the search bar and get directed to the smorgasbord of your silo). ${ }^{1}$ Industry sponsored sessions $(n=46)$ and non-commercial symposia $(n=13)$ were also delivered online throughout the meeting, but the virtual exhibition (which you could stroll through as an avatar) closed at the end of the meeting and is no longer accessible. This year's abstracts 1-264 and 265-977 were presented in 48 oral and 6 poster sessions, respectively. Abstracts, electronic posters and oral presentations can be viewed via the EASD virtual meeting. ${ }^{1}$

Table 1 Award lectures at EASD 2020

\begin{tabular}{|c|c|c|}
\hline Prize & Lecturer & Title (day of presentation) \\
\hline $\begin{array}{l}\text { 52nd Claude } \\
\text { Bernard Lecture }\end{array}$ & $\begin{array}{l}\text { Takashi Kadowaki } \\
\text { Japan }\end{array}$ & $\begin{array}{l}\text { What is type } 2 \text { diabetes? A long journey to seek the truth } \\
\text { (Tuesday) }\end{array}$ \\
\hline $\begin{array}{l}\text { 35th Camillo } \\
\text { Golgi Lecture }\end{array}$ & $\begin{array}{l}\text { Naveed Sattar } \\
\text { UK }\end{array}$ & $\begin{array}{l}\text { Cardiovascular risks in diabetes: new insights from simple } \\
\text { observations (Tuesday) }\end{array}$ \\
\hline $\begin{array}{l}\text { 14th Albert } \\
\text { Renold Lecture }\end{array}$ & $\begin{array}{l}\text { Guy A Rutter } \\
\text { UK }\end{array}$ & $\begin{array}{l}\text { Metabolic and functional specialisation of the pancreatic } \\
\text { beta cell (Tuesday) }\end{array}$ \\
\hline $\begin{array}{l}\text { 6th EASD-Novo } \\
\text { Nordisk } \\
\text { Foundation } \\
\text { Diabetes Prize } \\
\text { for Excellence }\end{array}$ & $\begin{array}{l}\text { Jens C Brüning } \\
\text { Germany }\end{array}$ & $\begin{array}{l}\text { Brain insulin action in CNS-dependent control of } \\
\text { metabolism (Wednesday) }\end{array}$ \\
\hline $\begin{array}{l}\text { 55th Minkowski } \\
\text { Lecture }\end{array}$ & $\begin{array}{l}\text { Gian P Fadini } \\
\text { Italy }\end{array}$ & $\begin{array}{l}\text { Should I stay or should I go? The bone marrow and stem } \\
\text { cell traffic in diabetes (Thursday) }\end{array}$ \\
\hline
\end{tabular}

\section{Highlights}

As usual it was worth dropping in on the prize lectures (Table 1), and this year moving between 'must see' simultaneous sessions was swift and sweat-free (a brief cardiorespiratory workout being unnecessary). Trials which warranted devoted sessions at EASD are listed in Table 2.

LIBERATES recruited 141 insulin and/or sulfonylurea-treated type 2 diabetes patients within 5 days of a myocardial infarction (MI) and assigned them (1:1) to either interstitial Flash glucose monitoring or conventional selfmonitoring of blood glucose for 3 months. There was no difference in $\mathrm{HbA}_{1 c}$ between patients using either monitoring system, although Flash monitoring improved glycaemic time in range, significantly lowered the risk of hypoglycaemia and was associated with higher treatment satisfaction.

The session on the STEP programme described the four studies undertaken to evaluate the efficacy and safety of once-weekly semaglutide (2.4 mg sc) in over 5,000 overweight/obese people with (STEP 2) and without type 2 diabetes. Over 68 weeks, semaglutide-treated subjects lost significantly more weight, but those with type 2 diabetes only lost $9.6 \%$ of their body weight from baseline whereas non-diabetic subjects lost $14.9-17.4 \%$.

The cardiovascular outcome trial (CVOT) VERTIS-CV initially reported at ADA 2020 (ertugliflozin was non-inferior - but not statistically superior - to usual care in reducing the composite endpoint of $\mathrm{CV}$ death, $\mathrm{MI}$ or 
Table 2 Trials with devoted sessions

Trial
LIBERATES
improving gLucose control in patlents with diaBEtes
following myocaRdial infArction: the role of a novEl
glycaemic monitoring Strategy
STEP
Semaglutide Treatment Effect in People with obesity
VERTIS CV
Cardiovascular outcomes following ertugliflozin treatment
in type 2 diabetes mellitus participants with vascular
disease
EMPEROR-Reduced
EMPagliflozin outcomE tRial in patients with chrOnic heart
failure with Reduced ejection fraction
DAPA-CKD
A study to evaluate the effect of DAPAgliflozin on renal
outcomes and cardiovascular mortality in patients with
Chronic Kidney Disease

Presenters (day of presentation)

R F Storey, D D Stocken, R A Ajjan (Wednesday)

L M Kaplan, M J Davies, J P Wilding, L Czupryniak (Tuesday)

R E Prately, B Charbonnel, F Cosentino, D Z Czerney, D K McGuire (Wednesday)

J Butler, M Packer, S D Anker, G Filippatos, C J Bailey (Thursday)

P Rossing, D C Wheeler, H J L Heerspink, C Mathieu (Friday) stroke), and at EASD additional data showing the renal benefits of ertugliflozin (eg, regression in chronic kidney disease (CKD), a reduction in progression to albuminuria) were presented by Professor David Cherney.

DAPA-CKD, which originally reported at ESC 2020, noted that dapagliflozin treatment significantly reduced the risk of a composite of a sustained decline in the estimated glomerular filtration rate (eGFR) of at least $50 \%$, end stage renal disease or death from renal or CV causes in patients with CKD with and without type 2 diabetes.

EMPEROR-Reduced, which also reported initially at ESC 2020, in patients with estab- lished heart failure with reduced ejection fraction (HFrEF) noted a reduction in the annual rate of decline in eGFR in subjects taking empagliflozin. Empagliflozin significantly reduced hospitalisation for $\mathrm{HF}$, reducing the risk in subjects with and without diabetes by $28 \%$ and $22 \%$, respectively - observations similar to those reported in DAPA-HF.

The newer non-insulin glucose-lowering agents - namely, the sodium glucose cotransporter 2 inhibitors (SGLT2i) and incretins - continued to create particular interest. The EASD/ESC Symposium considered the learnings since the first SGLT2i CVOT reported at EASD 2015 in Stockholm, and an oral session put these agents "at the heart of the matter" (OP21, Abstracts 121-126), as did several posters. For example, poster sessions 43 and 44 (Abstracts 557-576) provided further analyses of the CVOTs and gave mechanistic insights, including SGLT2i-induced renoprotection. There were similar sub-analyses and observations regarding incretin-based therapies (PS 45-48, Abstracts 577-609) including suggestions of renoprotection. In the light of increasing information on the actions of newer agents, especially secondary prevention of CV disease, the question arises, which guidelines should be followed? ESC or EASD/ADA? Friday's Michael Berger Debate offers interesting perspectives.

\section{The future}

EASD 2021 is scheduled to be held in Sweden on 27 September to 1 October. Hopefully next year we will be able to choose between virtual or actual attendance. Where are we more likely to meet? The sofa (socially distanced) or Stockholm?

\section{References}

1. EASD virtual meeting site. https://www. easd.org/virtualmeeting/home.html

Correspondence: Dr Caroline Day, Visiting Fellow, Diabetes Group, Aston University, Birmingham B4 7ET, UK E-mail: cday@mededuk.com

http://dx.doi.org/10.15277/bjd.2020.272 Br J Diabetes 2020;20:170-171

\section{The British Journal of Diabetes Quality Improvement in Diabetes Award 2021}

The British Journal of Diabetes, in conjunction with the Association of British Clinical Diabetologists (ABCD) and the Young Diabetologist and Endocrinologist Forum (YDEF) are pleased to announce the launch of our inaugural quality improvement in diabetes award programme.

Have you changed your service recently?

Have you got evidence that the changes you have implemented have improved outcomes for your patients?

Do you think other services would benefit from sharing your knowledge or adopting similar approaches?
We are asking for submissions of write-ups of quality improvement projects from teams around the country. Although aimed primarily at trainees (specialist registrars), all members of the diabetes MDT or those in internal medicine training (IMT) should feel free to submit their work.
This is a fantastic opportunity to share your work, gain publication and potentially win an award. A prize of $f 250$ each as well as publication in the British Journal of Diabetes has been made available for the top 3 quality-improvement projects.
WHAT DO - Write-up of your quality improvement project following the format here: WE ASK? http://squire-statement.org/index.cfm?fuseaction=Page. ViewPage\&PagelD=471

- Deadline: 28th February 2021
Any questions please e-mail: T.Crabtree@nhs.net 